\title{
QUICK-FREEZE DEEP ETCH REPLICA OBSERVATION OF THE GYTOSKELETON COMBINED WITH ANTIBODY DECORATION
}

\author{
Nobutaka HIROKAWA \\ Department of Anatomy, Faculty of Medicine, University of Tokyo, \\ Bunkyo-ku, Tokyo 113
}

The recently developed quick freeze, deep-etch technique (QF.DE) enables us to observe three-dimensional architecture of cytoskeletal elements at a resolution high enough to pick out macromolecular structures. The chemical nature of the cytoskeletal polymers can also be investigated by in-situ decoration with antibodies or immunocytochemistry in conjunction with the QF.DE. Here we present molecular structures of actin, and intermediate filaments, associated cytoplasms by these approaches.

Actin Associated Cytoplasm

The brush border of the intestinal epithelial cells is a good model system to study cytoskeletal organization of the actin-associated cytoplasm in the cellular cortex. An extensive crosslinker system was demonstrated among rootlet actins, plasma membrane, intermediate filaments, and vesicles in the terminal webs by the QF.DE electron microscopy. Antibody decoration studies using ferritin labeled second antibodies displayed that fodrin is a component of crosslinkers between rootlet actins and those between plasma membrane and rootlet actin and that myosin is a component of crosslinkers between rootlet actins at the basal region of the terminal web.

Intermediate Filaments Associated Cytoplasm

Intermediate filaments in various kinds of cells (intestinal epithelial cells, glial cells etc) look similar in appearance. They are $\sim 11 \mathrm{~nm}$ in diameter and smooth in contour. However, the intermediate filaments in the nerve cells are different in shape. Numerous straight and short crossbridges $(20 \sim 50 \mathrm{~nm}$ in length) link neurofilaments with each other especially in the axon. Short crossbridges are also found between neurofilaments and membrane organelles and between neurofilaments and microtubules. To understand the chemical nature of the neurofilamentassociated crosslinks, in-situ decoration with antibodies against the three major neurofilament polypeptides (195KD, $145 \mathrm{KD}$ and $73 \mathrm{KD})$ was carried out in conjunction with the QF.DE technique. Each antibody assumed a characteristic distribution: anti-73KD decorated the neurofilament core uniformly by not the crossbridges; anti $145 \mathrm{KD}$ also decorated the core, but less uniformly and sometimes spanned over the bases of the crossbridges; in contrast, anti $195 \mathrm{KD}$ decorated the crossbridges between the neurofilaments. These observations show that the $195 \mathrm{KD}$ polypetide is a component of the inter-neurofilament crossbridges. Thus the QF.DE technique combined with antibody decoration in situ could be a promising approach to understand the molecular structure and chemical nature of the cytoskeletal architecture in the cell. 


\section{REFERENGES}

1. Heuser, J. E. and Salpeter, S. R.: Organization of acetylcholine receptors in quick-frozen, deep-etched, and rotary-replicated Torpedo postsynaptic membrane. J. Cell Biol. 82; 150-173, 1979.

2. Hirokawa, N. and Heuser, J. E.: Quick-freeze, deep-etch visualization of the cytoskeleton beneath surface differentiations of epithelial cells. J. Cell Biol. 91; 339-349, 1981.

3. Hirokawa, N., Tilney, L. G., Fujiwara, K. and Heuser, J. E.: The organization of actin, myosin and intermediate filaments in the brush border of intestinal epithelial cells. J. Cell Biol. 94; 425-443, 1982.

4. Hirokawa, N.: The crosslinker system between neurofilaments, microtubules and membranous organelles in frog axons revealed by quick freeze, freeze fracture, deep etching method. J. Cell Biol. 94; 129-142, 1982.

5. Hirokawa, N., Cheney R. and Willard M. B.: Location of a protein of the fodrin-sepctrin-TW 260/240 family in the mouse intestinal brush border. Cell 32; 953-965, 1983.

6. Hirokawa, N., Gliskman, M. A. and Willard, M. B.: Organization of mammalian neurofilament polypeptides within the neuronal cytoskeleton. J. Cell Biol. 98; 1523-1536, 1984. 